\title{
Article \\ Barriers and Enablers for Continuous Improvement Methodologies within the Irish Pharmaceutical Industry
}

\author{
Olivia McDermott ${ }^{1, *}$, Jiju Antony ${ }^{2} \mathbb{C}$, Michael Sony ${ }^{3} \mathbb{C}$ and Stephen Daly ${ }^{4}$ \\ 1 College of Science \& Engineering, National University of Ireland, H91 TK33 Galway, Ireland \\ 2 Department of Industrial \& Systems Engineering, Khalifa University, \\ Abu Dhabi P.O. Box 127788, United Arab Emirates; jiju.antony@ku.ac.ae \\ 3 Department of Mechanical \& Marine, Namibia University of Science and Technology, \\ Windhoek 10005, Namibia; emailofsony@gmail.com \\ 4 Department of Life Sciences, Institute of Technology Sligo, F91 YW50 Sligo, Ireland; Daly.Stephen@itsligo.ie \\ * Correspondence: olivia.mcdermott@nuigalway.ie
}

check for updates

Citation: McDermott, O.; Antony, J.; Sony, M.; Daly, S. Barriers and Enablers for Continuous Improvement Methodologies within the Irish Pharmaceutical Industry. Processes 2022, 10, 73. https:// doi.org/10.3390/pr10010073

Academic Editor: Jun-Ho Huh

Received: 8 December 2021

Accepted: 24 December 2021

Published: 30 December 2021

Publisher's Note: MDPI stays neutral with regard to jurisdictional claims in published maps and institutional affiliations.

Copyright: (c) 2021 by the authors. Licensee MDPI, Basel, Switzerland. This article is an open access article distributed under the terms and conditions of the Creative Commons Attribution (CC BY) license (https:// creativecommons.org/licenses/by/ $4.0 /)$.

\begin{abstract}
This study aims to investigate the barriers that exist when implementing continuous improvement methodologies, such as Lean Six Sigma (LSS), within the Irish Pharma industry. The main finding of this study is that $45 \%$ of participants perceived that a highly regulated environment could be a barrier to continuous improvement implementation, while $97 \%$ of respondents utilised Continuous improvement (CI) methods, such as Lean, Six Sigma, and LSS, within their organisations. While the International Conference of Harmonisation integrates CI into its Pharmaceutical Quality Systems (PQS) regulations, the highest motivation for $\mathrm{CI}$ implementation amongst the Irish Pharma industry is to improve Productivity and Quality. The main obstacles highlighted for CI implementation in Pharma attributed to stringent regulatory regimes were fear of extra validation activity, a compliance versus quality culture, and a regulatory culture of being "safe". Another relevant finding presented in this paper is that participants CI LSS tools are very strongly integrated into the pharma industries corrective and preventative action system, deviations, and internal audit systems. Limitations of the research are that all the data collected in the survey came from professionals working for multinational Pharmaceutical companies based in Ireland. The authors understand that this is the first research focused on the barriers and status of $\mathrm{CI}$ initiatives in the pharmaceutical industry. The results of this study represent an important step towards understanding the enablers and obstacles for the use of continuous improvement methodologies in pharmaceutical manufacturing industries on a global scale.
\end{abstract}

Keywords: continuous improvement; pharmaceutical industry; biopharmaceutical industry; lean six sigma; 21 CFR 211; 21 CFR 210; International Conference for Harmonisation (ICH); Pharmaceutical Quality System (PQS); European Medicines Agency; Food and Drug Administration

\section{Introduction}

Manufacturing excellence in the Pharmaceutical and Biopharmaceutical industry is a hallmark of Ireland's success in the sector. This sector is constantly driving growth, and Ireland has seen continued capital investment averaging $€ 1$ billion per annum over the last 10 years [1]. There are over 85 pharma companies in Ireland, with 9 of the world's top 10 pharma companies operating in Ireland. Ireland is now the largest net exporter of pharmaceuticals in the EU, accounting for over $50 \%$ of all exports from the country [2]. The sector employs more than 30.000 people in Ireland [3]. At the EU level, Pharmaceutical manufacturers contributed $€ 37$ billion in 2019, and the sector provided 800,000 direct jobs and a $€ 109.4$ billion trade surplus [4]. The biggest export markets for Irish Pharma products are Europe and the USA, receiving 36\% and 30\% of Irish pharma exports, respectively [5].

By their very nature, pharmaceutical medicines and drugs are dangerous if misused or prescribed incorrectly and can have many side effects, including fatalities. Regulation 
affects every aspect of the pharmaceutical sector, including pre-marketing development, marketing authorisation, manufacturing, and post-marketing activities [6]. The manufacturing of pharmaceutical products is thus subject to stringent regulatory strictly controls by authorities to ensure product safety, Quality, and efficacy. In addition, manufacturers must conform to the regulatory requirements of the geographical region in which medicines and drugs are being manufactured and the regulatory regimes to which they are being exported or marketed for use $[7,8]$. The industry is one in which revenues are decreasing because of competition from generic alternatives [9], while the costs of $R \& D$ are rising and competition is increasing [10]. Hence the Pharma industry is increasingly adopting CI as a means of improving efficiency and reducing costs.

Dale [11] define continuous improvement as "the means of improvement to people and process performances needs to be continually sought and monitored". The implementation of continuous improvement methodologies must consider the development of a culture for continuous improvement, which aims to eliminate waste in all processes, involving all employees, without necessarily having a significant financial expenditure [12]. Many continuous improvement methods are utilised by organisations in all types of industry, with Lean, Six Sigma, and Lean Six Sigma (LSS) evolving as the CI methodologies of choice in recent years [13].

While CI methodologies have been deployed widely in many organisations, the application in highly regulated industries such as the Pharmaceutical industry is not as researched or studied as in other sectors [13-17]. Examples of some large Pharma companies which have Lean programs include Astra Zeneca, Johnson \& Johnson, and Pfizer [18].

There have been some studies on Lean application in Pharma [14], for example, Pharma industry readiness for Lean [19], and how Lean can be practiced in a Pharma environment [20]. Pharmaceutical companies are secretive by nature and are cautious about releasing any information that may put them at a disadvantage to their competitors [21]. Several studies on $\mathrm{CI}$ in the highly regulated and comparable medical device industry have highlighted the regulated nature of the industry as a barrier to CI [20,22,23]. Furthermore, although organisations have widely implemented CI, sustaining the momentum of CI activities have been a challenge [23]. This research contributes to a gap in published literature by investigating the critical failure factors ( $\left.\mathrm{CFF}^{\prime} \mathrm{s}\right)$ and benefits for $\mathrm{CI}$ methodology deployment and identifying the types of CI methodologies utilised for deploying CI in the Irish Pharmaceutical sector. Further, the study also investigates if the highly regulated nature of the pharmaceutical sector is an additional CFF and barriers to embracing CI. This research will also explore the extent of continuous improvement methods such as Lean, Six Sigma and Lean Six Sigma within the industry and the type of CI tools utilised. The authors are asking the following research questions:

1. What are the CI methods and tools utilised for $\mathrm{CI}$ in the Irish Pharmaceutical industry?

2. What are the drivers and benefits for use of $\mathrm{CI}$ within the Pharma industry?

3. What are the CFF's for deployment of $\mathrm{CI}$ in the Irish Pharma industry?

4. Does the highly regulated nature of the Irish Pharmaceutical industry pose a unique and significant barrier to CI methodology deployment and culture?

The remainder of the paper is as follows; Section 2 describes the literature, followed by research methodology in Section 3. Next, the results are presented in Section 4, followed by a discussion and implications in Section 5 . Finally, the conclusion, limitations, and scope for future research are outlined in Section 6.

\section{Literature Review}

\subsection{Pharmaceutical Industry \& Regulatory Background}

The primary difference between biopharmaceuticals and traditional pharmaceuticals is the method the drugs are produced: The former are manufactured in living organisms such as bacteria, yeast and mammalian cells, whereas the latter are manufactured through a series of chemical synthesis [24]. The FDA defines a drug, in part, as "intended for use in the diagnosis, cure, mitigation, treatment, or prevention of disease" and "articles (other 
than food) intended to affect the structure or any function of the body of man or other animals [13]. Thus, due to the importance of drugs (US FDA term) and medicines (more utilised in Europe by the European Medicines Agency) and the dangers they can pose and the benefits to humans in their use, their manufacture is highly regulated.

In the European Union, of which Ireland is a part and globally across other jurisdictions, drugs and medicines are stringently regulated by laws that govern the safety, efficacy, and Quality across their lifetime, pre-and post-market [25].

Before marketing, a drug manufacturer must obtain a marketing authorisation in the relevant jurisdiction they want to manufacture in and in any jurisdiction in which they want to export products. For example, in Europe, medicines and the European pharmaceutical manufacturers are regulated by the European Medicines Agency (EMA), while the Food and Drug Administration (FDA) regulate the US manufacturers and anyone with a market authorisation to export into the USA.

According to the Irish Health Products Regulatory Authority (HPRA) (and by association the EMA), the risk of using a medicinal product should be acceptable and reasonable, taking into account that the use of any medicine carries a risk, which should be considered in the light of the likely benefit. Thus HPRA (or the relevant global regulatory authority) must be kept informed of any new safety data which emerges (and which might affect the benefit/risk balance [26].

An initial regulatory submission or drug marketing authorisation application to authorities includes a general description of the overall drug manufacturing strategy [27]. It requires evidence of an approach to process validation where a manufacturing process (or supporting utility systems) performance is continuously monitored, evaluated, and adjusted as necessary. Witcher emphasised the importance of proactive use of a broad range of quality and process development tools throughout the manufacturing lifecycle. These tools are most effective when integrated using process validation guidelines [28].

Any changes implemented after a drug marketing authorisation has been achieved which may affect drug manufacturing processes, materials, tests, monitoring, equipment and which may be implemented or proposed as part of CI program actions or even cause minor changes in procedures must be assessed for risk [29]. Risk assessment ensures the product purposes, functionality, efficacy, Quality or safety is not affected. Actions generated by CI initiatives, for example, may involve submissions or notifications to regulatory bodies as these changes may impact the drug performance and affect the manufacturers originally approved market authorisation status [19,21].

When implementing any change or variation type or CI, there is always fear that a quality defect may occur which needs to be reported or recalled in a formal recall (all regulatory jurisdictions have a form of recall procedures and processes). Recalls create unwanted attention on the manufacturer by the regulatory authorities and create a loss of revenue and increased workload and resources in providing regulatory root cause and corrective actions (RCCA) [30]. The financial implication of drug recalls also are substantial. For example, Johnson and Johnston, one of the world's largest producers of healthcare products, reported a $\$ 900$ million reduction in 2010 sales resulting from product recalls [31]. A 30-month study conducted in 2016 on FDA drug recalls found the top 5 drug recall reasons were contamination, mislabeling, adverse reaction, defective product, and incorrect potency [32]. Hence manufacturers are adverse to change, risk and associated CI that may impact product quality for fear of unwanted regulatory body attention and potential recalls. Any proposed change or CI should be managed as part of a formal change management process for pharmaceutical manufacturing, and processes should incorporate an assessment of potential risks [27].

Regulatory authority milestones and processes are a well-recognised bottleneck in terms of time, resources and cost for pharmaceutical manufacturers $[8,25]$. One of the most significant challenges for any regulatory agency regulating a highly technical field is maintaining a high enough level of scientific expertise to evaluate changes correctly. This problem is acute for agencies regulating the pharmaceutical industry [32]. Irish pharma- 
ceutical manufacturers could be subject to multiple audits a year by different regulatory authorities from countries into which they export products. Regulatory bodies from these countries may audit to assess the companies PQS on behalf of the relevant regulatory authorities. This increases pressure on manufacturers who must be "audit-ready", and resources can be taken up in audit readiness and participation. Thus a focus may be more on compliance than improvement [18]. However, EMA and its European and international partners increasingly cooperate to share information on GMP inspections of manufacturers outside the participating countries and organise joint inspections of manufacturing sites of common interest [33]. The FDA and the EU have collaborated since May 2014 to evaluate how each regulator inspects drug manufacturers and assesses the risk and benefits with mutual recognition agreements (MRA's) on drug inspections [34]. While this initiative has not eliminated GMP inspections, it has aided in reducing the number of duplicate inspections, saving costly inspectional resources and reducing the number of repeated, often similar inspections. Finally, it demonstrates the effort by regulatory jurisdictions to harmonise processes and thus reduce the regulatory burden on manufacturers.

There is an international trend towards global regulatory harmonisation of pharmaceuticals $[35,36]$. Harmonisation aims to eliminate duplication across regulatory processes and documentation, ensure standardisation and mutual recognition among jurisdictions of regulatory approvals. In 1990, regulatory agencies and organisations from the US, Europe, and Japan established the International Conference on Harmonization (ICH) of Technical Requirements for Registration of Pharmaceuticals for Human Use to promote the harmonisation of pharmaceutical regulations related to product safety, Quality, and efficacy [37]. The European Medicines Agency (EMA) has also improved the harmonisation of the approval process for drugs with its cross European regional decentralised and centralised mutual recognition authorisation processes [38]. The FDA and other regions participating in the ICH have endeavoured to emphasise flexible regulatory approaches, for example, to facilitate risk-based regulatory decisions (reviews and inspections) manufacturing process improvements, within the approval that was given for their market authorisation dossier applications. This flexible regulatory approach within ICH guidelines is encouraged with the advantages of no further regulatory review and a reduction of post-approval submissions [39,40].

The ICH Guidelines on a Pharmaceutical Quality System (PQS), known as ICH 10, states that "Implementation of ICH Q10 throughout the product lifecycle should facilitate innovation and continual improvement and strengthen the link between pharmaceutical development and manufacturing activities" [41]. Management are also directed to "advocate continuous improvement", and Section 3 has a "Change Management Process" category. ICH 10 [41] further states that "The change management system ensures continual improvement is undertaken in a timely and effective manner". While this is positive in terms of $\mathrm{CI}$, the following statement "It should provide a high degree of assurance there are no unintended consequences of the change"; can mean there is an over-focus on the risk of the change or $\mathrm{CI}$ and this a cautious approach to $\mathrm{CI}$.

\subsection{Regulatory Environments a Specific CFF to CI Deployment}

There are some case studies on LSS and CI in pharma organisations. However, a recent case study published in 2021 on LSS in an Irish pharmaceutical company demonstrated an example of where an appropriate corrective action was identified but not taken due to fear of a having to enter a lengthy regulatory submission and an almost certain requirement to revalidate the process [13]. Chowdary and George [14] have highlighted the lack of Lean application in pharma clean room environments describing it as "feeble". Another study by Boylan et al. in 2021 described its aim of redesigning its design control process without affecting regulatory compliance [42].

In recent years, many commentators, particularly those with industry ties, have criticised regulators for overburdening the pharmaceutical industry and hindering its ability to develop, manufacture and market new drugs [32,43]. Regulatory barriers, regulatory 
practices, and concepts; issues associated with inspecting facilities with new technologies and making changes after application approval; and the lack of international harmonisation of regulatory convergence have all been identified as affecting CI or innovation [43]. As part of the international harmonisation effort, the ICH, the FDA and EMA have recognised that regulatory regimes can lend to a compliance and risk-averse culture instead of a CI culture. Subsequently, the ICH has recently published a guideline known as ICH Q12 on technical and regulatory considerations for the pharmaceutical product lifecycle [44]. This guidance focuses on managing certain post-approval (manufacturing process) changes within the individual pharmaceutical organisation's own remit and own PQS. These changes are proposed to be managed as part of the internal pharmaceutical quality system (PQS) only or as a regulatory notification (with no or limited prior approval by regulators) when a comprehensive risk assessment concludes that a proposed change introduces no risk to patient safety, product quality and efficacy. In other words, companies can manage more internal manufacturing process CI changes without the need for prior regulatory approval, provided they operate under a framework including an effective PQS, along with sound product and process knowledge and risk management practices [7].

Currently, ICH Q12 is in the implementation phase across the ICH regions. However, especially in the EU, revision of local regulations (the EU Variations Regulation) will have to be performed to fully implement the concepts of Q12 [39].

While ICH Q12 and previous harmonisation efforts will not remove regulatory burden but it may, in some cases, reduce it as it demonstrates steps by the regulatory authority to attempt to listen to industry stakeholders, remove elements of bureaucracy and aid improved and effective CI programs within a pharmaceutical organisations own QMS.

Continuous improvement is a valuable strategy for an organisation to improve productivity quality and, enhance products and services and attain a competitive advantage. The most common driver for pharmaceutical companies to adopt Lean is to improve the overall manufacturing efficiency [45].

There are several critical success factors for the deployment and implementation of CI methods such as LSS. Within the critical success factors identified, management commitment and support, clear communication, providing key resources and training, and organisational culture were identified as key [46]. On the other hand, there were many CFF's identified in CI deployment [47,48]. Albliwi et al. [47] highlighted that a lack of financial or physical resources has been cited as a critical failure factor for Lean deployment and can affect organisational readiness to embrace CI. Organisational culture is an important critical success factor for CI method implementation [49,50].

\section{Methodology}

The authors utilised an online survey for data collection targeted at Pharmaceutical organisations and staff working in Quality, regulatory, pharmacovigilance, manufacturing engineering, continuous improvement and other associated functions of the pharmaceutical life cycle. An online survey instrument was chosen to increase speed of data collection, ease of completion and it is a flexible, easily automated tool [51]. The online survey enabled the collection of a large amount of data from participants expediently. The survey (Appendix A) was divided into two sections. The first section part aimed to obtain general information about the respondents and their organisations. A specific question was asked, "Do you feel that a highly regulated Pharmaceutical environment stifles continuous improvement programs in your organisation?" to which the respondent could answer yes or no. If they answered Yes, they were then asked to tick various options (while the "no" respondents were directed to move on to another question) concerning why they felt regulated environments could be a barrier to CI.

The second section of the online survey was devoted to eliciting information about various aspects of the integration, use, and types of LSS and CI tools within Pharmaceutical organisations. Continuous improvement, Quality, and other professionals working in various pharmaceutical industry functions were contacted via LinkedIn and invited to 
participate in this study via the LinkedIn personal messaging system [52]. Piloting of the survey was conducted prior to dissemination to ensure the design and approach was appropriate. The proposed online survey questions and online format was first piloted $[47,50]$ with ten professionals from the pharmaceutical industry who more than ten years of experience in had implementing continuous improvement in their organisations. The comments and feedback from the pilot study were subsequently used to review the survey questions and make the questions more readable and relevant to the research.

The survey, once revised, was sent out to over 150 professionals working in Pharmaceutical and Biopharmaceutical organisations in various roles and functional areas that support the development, design and manufacturing of drug products. Distributing to a wide variety of functional professionals enabled an organisational viewpoint across the manufacturing product lifecycle in the respective Pharmaceutical organisations. A total of 80 valid responses out of 150 distributed survey links were collated over 12 weeks, yielding a response rate of $53 \%$. Many research studies have indicated $20 \%$ as a sufficient survey response rate [53]. The number of years of experience of the survey respondents is given in Figure 1. The respondents were also asked about their length of experience within the Pharma industry, and $76 \%$ of respondents had over two years of experience.

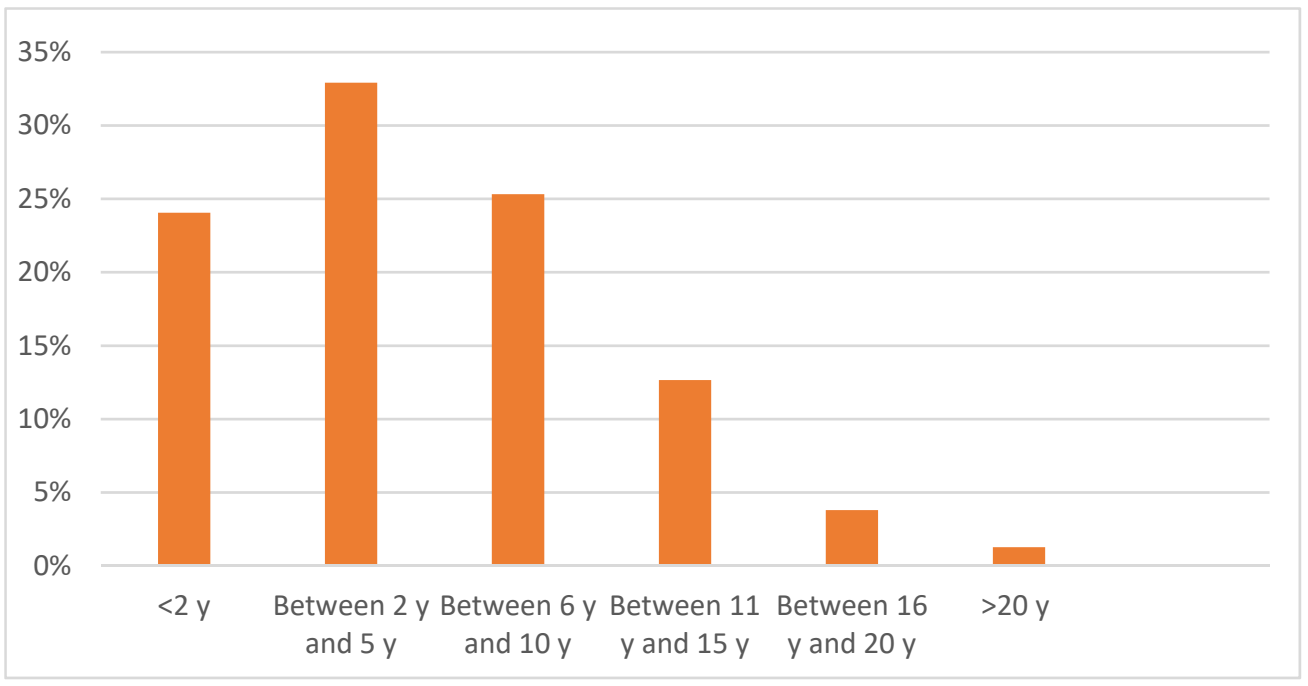

Figure 1. Years of experience of respondents in working in the pharma industry.

\section{Results}

The respondents were asked basic questions about their location (which was distributed in Ireland) and industry type, whether pharmaceutical or biopharmaceutical. The analysis plan is detailed in Figure 2, given below.

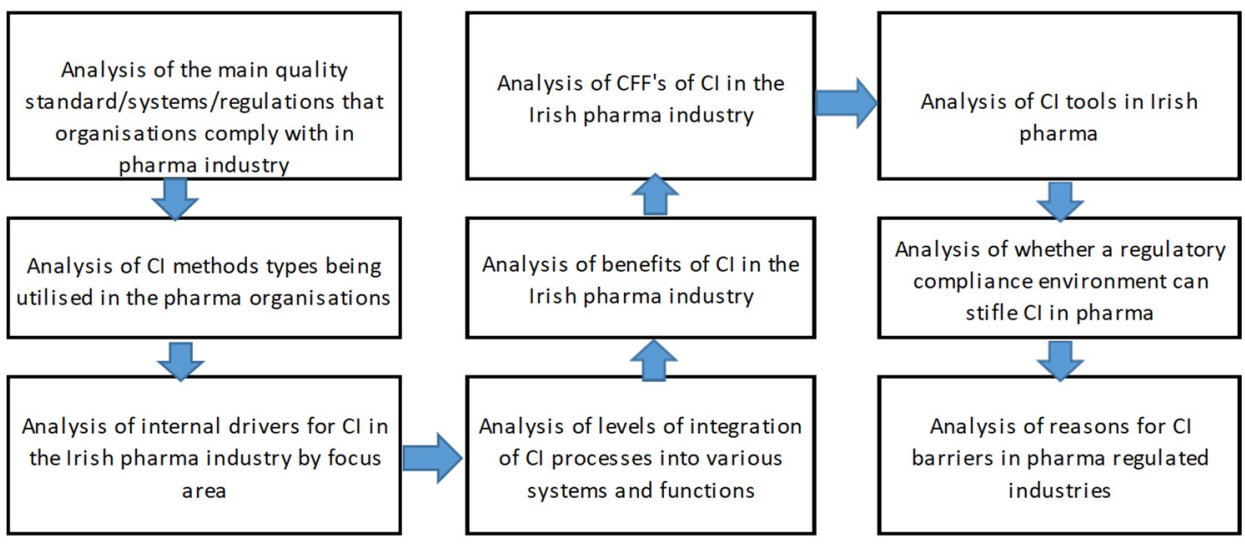

Figure 2. Research Analysis Plan. 
As shown in Table 1, the respondents came from a wide range of functional areas within their organisations. These functional areas contribute to the successful manufacturing and product distribution associated with pharmaceutical manufacture. The majority of respondents, nearly one in four, worked directly with the manufacturing floor (24\%) as pharmaceutical or biopharma production operators or supervisors. The functional areas that support pharmaceutical production included manufacturing or process engineering (14\%), operations quality (9\%), validation engineering (9\%), and QC laboratories (9\%), followed by continuous improvement and supply chain/logistics functions at $8 \%$ each. Thus, there was a representative selection of participants from all functional areas within a manufacturing facility. Unfortunately, not all functional support areas, such as HR, pharmacovigilance, and other support functions, such as R\&D and supplier quality, were as widely represented as those very involved with direct pharmaceutical GMP production lines. However, continuous improvement methodologies tend to be traditionally more strongly associated with the manufacturing floor, so there was a good representation of respondents familiar with CI methods.

Table 1. Functional Areas within Pharma of the respondents.

\begin{tabular}{cc}
\hline Functional Areas of Respondents & $\%$ \\
\hline Production/Operations & $24 \%$ \\
Manufacturing / Process Engineering & $14 \%$ \\
Operations Quality & $9 \%$ \\
Validation & $9 \%$ \\
QC Lab Role & $9 \%$ \\
Continuous Improvement & $8 \%$ \\
Supply Chain/Logistics & $8 \%$ \\
Project Management & $6 \%$ \\
Regulatory & $5 \%$ \\
Quality Systems & $5 \%$ \\
Warehouse/Shipping & $1 \%$ \\
Maintenance & $1 \%$ \\
Sales & $1 \%$ \\
R\&D/Design & $0 \%$ \\
surveillance & $0 \%$ \\
Supplier Quality & $0 \%$ \\
Technical Writer & $0 \%$ \\
HR & $0 \%$ \\
\hline
\end{tabular}

Respondents were also asked to select from a range of possible generic or pharmaceutical quality standards or regulatory systems that they were certified to or in compliance with (Table 2). Respondents could select one response or all that applied from a range of examples, including 21 CFR part 211 or part 10, ISO 9001:2015, or ICH systems.

Table 2. Quality System and/or Good Manufacturing practise regulations/guidelines adhered to by Irish pharma organisations.

\begin{tabular}{cc}
\hline Quality System & $\%$ \\
\hline 21 CFR 211 & $28 \%$ \\
\hline ISO 9001:2015 & $25 \%$ \\
\hline ICH Q10 Pharma Quality System & $25 \%$ \\
\hline 21 CFR 210 & $10 \%$ \\
\hline ICH Q7 (ICH GMP for API & $10 \%$ \\
\hline Don't know & $2 \%$ \\
\hline
\end{tabular}


As the majority of Irish pharmaceutical companies export into Europe and are licenced to export into the USA, they are often in compliance with both European regulations and U.S. FDA regulations and other global regulatory regimes depending on their export markets. Respondents were given options related to the International Standard Organisation (ISO) standard for quality management systems, which can be applied to any organisational product or service, known as ISO 9001:2015. Other choices listed included the FDA Code of Federal Regulations (CFR) current good manufacturing practice (cGMP) regulations for finished goods pharmaceuticals (21 CFR Part 211) as well as the FDA CFR cGMP regulations for manufacturing, packing, or holding of drugs (21 CFR Part 210).

The European Medicines Agency publishes scientific guidelines on human medicines that the International Council harmonises for Harmonisation of Technical Requirements for Registration of Pharmaceuticals for Human Use (ICH). The EMA requires that pharmaceutical manufacturers follow the ICH Guideline Q10 on Pharmaceutical Quality System (PQS) requirements in relation to their QMS. There is also a guidance called the ICH Q7 Good manufacturing practice for active pharmaceutical ingredients (API). Regional GMP requirements, the ICH Q7 Guideline, "Good Manufacturing Practice Guide for Active Pharmaceutical Ingredients", and ISO quality management system guidelines form the foundation for the ICH Q10 PQS system [41].

While the FDA, the EMA and ICH have many guidelines related to drug development, manufacturing and product release, only the relevant guidelines related to GMP and QMS's were included in this study. As a result, some pharma organisations may have been certified to comply with more than one of the QMS or GMP guidelines, regulations or standards outlined in Table 2, depending on their export markets. Compliance to both FDA GMP, the aforementioned ISO standard, and the ICH Q10 guidance can help an organisation provide superior products, processes, and invaluable customer service. This will result in a safer and healthier drug-product pipeline and an improved financial bottom line for the industry [54].

Nearly one in three of the respondents (28\%) stated that they were in compliance with 21 CFR part 211 the US FDA regulations for cGMP for finished pharmaceuticals, with one in four or 25\% stating they had been certified to ISO 9001:2015 and a further one in four or 25\% stating they adhered to the ICH Q10 PQS. As ISO 9001 certification is the most widely utilised standard for any generic type, it is implemented widely but is not required by global regulatory pharma authorities. However, certification to ISO 9001:2015 demonstrates that a specific set of criteria for the quality management system has been created, maintained, and is supported by top management.

In relation to the types of CI methodologies utilised within the Irish pharma industry, respondents were questioned on "which CI methodologies are you applying within your pharmaceutical organisation?" As demonstrated in Figure 3, 51\% of respondents indicated that they utilised Lean, Six Sigma, and LSS, with 29\% stating they used only LSS. In total, $97 \%$ of respondents stated that they used CI methodologies. Only 3\% of respondents stated that none of the aforementioned CI methodologies are utilised in their organisations. Those respondents are likely based in non-manufacturing-related functions or support functions that may not regularly use CI methods.

The internal reasons for using CI in Irish pharma organisations were the respondents' next question. The respondents were asked to rate whether productivity, customer focus, quality, regulatory, and safety reasons were of a high, moderate, or low driver or not a driver at all for implementing CI in their organisations.

Productivity was seen as a high driver at 59\% and a driver at $33 \%$-there was an overwhelming consensus that a Productivity (92\% combined) focus drives CI in Irish Pharma. A Quality focus was nearly as high a driver of CI deployment as Productivity, with 55\% of respondents stating Quality was a high diver and 28\% stating that Quality was a driver (83\% combined). Both Productivity and Quality are more or less equally high as priorities for deploying CI initiatives. However, Customer focus, Financial and Safety were ranked as high drivers (all at $43 \%$ ). This suggests that while Productivity is more 
important to Pharma organisations than Quality, customer and safety is also high on these organisations priorities. Generally, the most common driver for pharmaceutical companies to adopt Lean is improving overall manufacturing Productivity and efficiency [45].

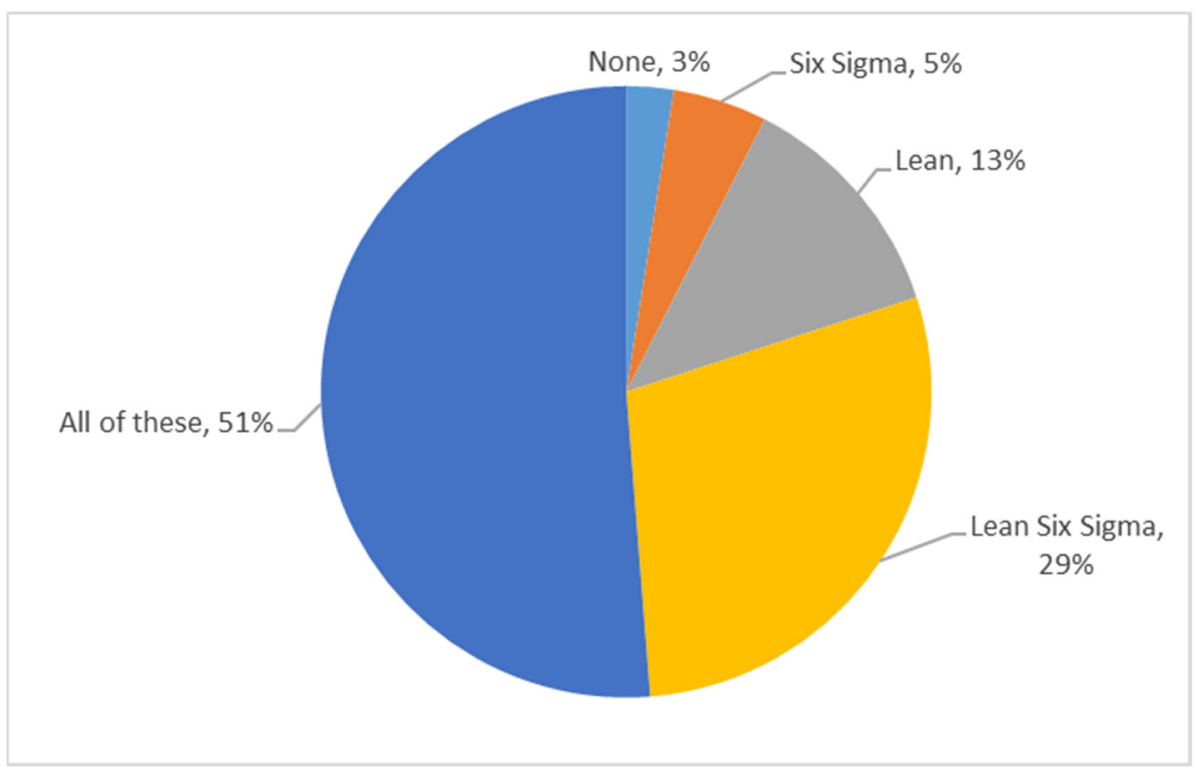

Figure 3. Percentage of the types of CI methodologies used in Irish pharmaceutical organisations.

A regulatory focus was seen as the lowest-ranked area in the high driver of CI methodology category at $28 \%$ but was the highest rank driver in the "driver" category at $35 \%$. This was a surprising finding given that the industry is so highly regulated to provide safe, quality, risk-free products, which are vital inpatient and general public treatments and can result in life-or-death situations. As these organisations adhere to so many regulations driven by external government authorities to ensure safe products are manufactured, it would be assumed that regulatory focus drove CI and not productivity. The results are outlined in Table 3.

Table 3. Internal drivers of $\mathrm{CI}$ in the Irish pharmaceutical industry by focus area.

\begin{tabular}{cccccc}
\hline & $\begin{array}{c}\text { High } \\
\text { Driver }\end{array}$ & Driver & $\begin{array}{c}\text { Moderate } \\
\text { Driver }\end{array}$ & $\begin{array}{c}\text { Low } \\
\text { Driver }\end{array}$ & $\begin{array}{c}\text { Does Not Drive a CI } \\
\text { Focus Whatsoever }\end{array}$ \\
\hline $\begin{array}{c}\text { Customer/Patient } \\
\text { focus }\end{array}$ & $43 \%$ & $25 \%$ & $18 \%$ & $10 \%$ & $4 \%$ \\
\hline Productivity & $59 \%$ & $33 \%$ & $11 \%$ & $0 \%$ & $0 \%$ \\
\hline Quality & $55 \%$ & $28 \%$ & $16 \%$ & $1 \%$ & $3 \%$ \\
\hline Regulatory & $28 \%$ & $35 \%$ & $28 \%$ & $11 \%$ & $14 \%$ \\
\hline Financial & $43 \%$ & $25 \%$ & $26 \%$ & $8 \%$ & $3 \%$ \\
\hline Safety & $43 \%$ & $31 \%$ & $15 \%$ & $6 \%$ & $4 \%$ \\
\hline
\end{tabular}

The next question asked was how integrated they felt that CI methodologies were in areas of their Quality Management System and within other departmental functions and systems. Respondents indicated that CI tools were "very integrated" into the following areas in order of ranking: (1) Corrective and Preventive Action System (CAPA) (49\%), (2) deviations (Non-Conformance) processes (46\%), (3) internal and external audit systems (44\%), and (4) pharmacovigilance systems (33\%). These four aforementioned areas also had a high "integrated" result. Only the management review process, the supplier quality CA process, and design assurance processes were ranked the lowest in having CI methods "very integrated" into their QMS systems. However, even these three areas had relatively 
high combined "very integrated" and "integrated" results of 49\% (management review process), 37\% (supplier quality CA processes), and 31\% (design assurance), suggesting that there was still a very high integration of CI methods within these areas even if CI was not as highly integrated there as in other areas. These results suggest a strong focus on CI methods and systems integrated throughout the pharma product lifecycle.

Management and leadership commitment is critical CSF's for CI [50,55]. Almost 1 out of every 2 respondents (49\%) felt that CI was very integrated and integrated in terms of being reviewed in the management review process. This suggests a reasonably strong commitment from Pharma leadership to improve their processes continuously.

The results are outlined in Figure 4. While Pharmaciovigilance systems are utilised to ensure product safety in the public domain, Customer Complaints and sourced supplier ingredients and components performance data can provide an important source of information and failure modes for feedback and input to CI programs. However, there were limited respondents from the supplier quality function in the survey, so perhaps the respondents' knowledge of the supplier quality systems may not be substantial.

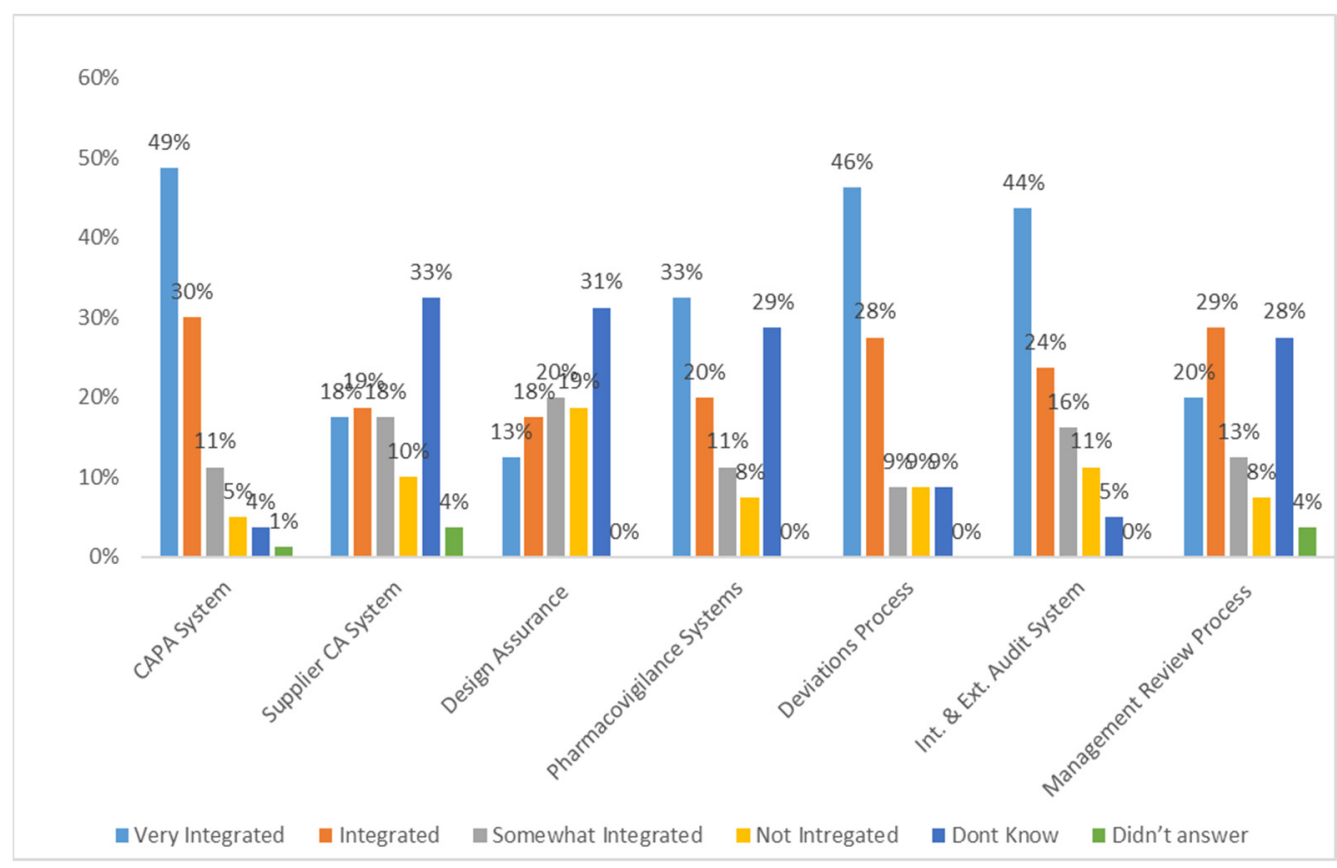

\begin{tabular}{|c|c|c|c|c|c|c|}
\hline & $\begin{array}{c}\text { Very } \\
\text { Integrated }\end{array}$ & Integrated & $\begin{array}{l}\text { Somewhat } \\
\text { Integrated }\end{array}$ & $\begin{array}{c}\text { Not } \\
\text { Intregated }\end{array}$ & Dont Know & $\begin{array}{l}\text { Didn't } \\
\text { answer }\end{array}$ \\
\hline CAPA System & $49 \%$ & $30 \%$ & $11 \%$ & $5 \%$ & $4 \%$ & $1 \%$ \\
\hline Supplier CA System & $18 \%$ & $19 \%$ & $18 \%$ & $10 \%$ & $33 \%$ & $4 \%$ \\
\hline Design Assurance & $13 \%$ & $18 \%$ & $20 \%$ & $19 \%$ & $31 \%$ & $0 \%$ \\
\hline Pharmacovigilance Systems & $33 \%$ & $20 \%$ & $11 \%$ & $8 \%$ & $29 \%$ & $0 \%$ \\
\hline Deviations Process & $46 \%$ & $28 \%$ & $9 \%$ & $9 \%$ & $9 \%$ & $0 \%$ \\
\hline Int. \& Ext. Audit System & $44 \%$ & $24 \%$ & $16 \%$ & $11 \%$ & $5 \%$ & $0 \%$ \\
\hline Management Review Process & $20 \%$ & $29 \%$ & $13 \%$ & $8 \%$ & $28 \%$ & $4 \%$ \\
\hline
\end{tabular}

Figure 4. Integration of CI into pharmaceutical QMS processes and other various functions.

As all regulatory authorities require manufacturers to show evidence of some corrective and preventative action or improvement system within their QMS, it is not surprising that CI tools are considered very integrated into all areas of the Irish Pharma manufacturers QMS's and PQS's. The purpose of the corrective and preventive action subsystem is to collect information, analyse information, identify and investigate product and quality problems, and take appropriate and effective corrective and preventive action to prevent their recurrence. 
As all regulatory authorities require manufacturers to show evidence of some corrective and preventative action or improvement system within their QMS, it is not surprising that CI tools are considered very integrated into all areas of the Irish pharma manufacturers QMSs and PQSs. The purpose of the corrective and preventive action subsystem is to collect information, analyse information, identify and investigate product and quality problems, and take appropriate and effective corrective and preventive action to prevent their recurrence. Moreover, a sizeable \% of respondents were from the manufacturing area functions and the quality function and so would be more familiar with the CAPA, deviations, and audit systems processes than other more non-manufacturing-related support functions.

Leadership plays an important role in strategy, particularly CI deployment and adoption $[48,49]$.

Lean programs aim to optimize global capacity and inventory while ensuring an uninterrupted supply of needed medicine [56]. The respondents were asked to pick the benefits of having CI in their organisations (Table 4); the respondents listed the following benefits in order of preference (1) improved Productivity (25\%), (2) improved product quality $(23 \%),(3)$ achieved cost savings (14\%). There seems to be almost equal importance placed on Productivity in hand with Quality. From the customer's perspective, the fact that a pharmaceutical plant is running with surplus capacity should have little consequences in the short term. The product will still be delivered on time, at the right Quality, and according to cGMP, but the plant with surplus capacity available has higher operating costs [18]. Thus it is more understandable that the benefits of CI related to customer needs and wants were ranked extremely low as if the plants have surplus capacity, customer needs are met, but operating costs are more of a priority. Cultural aspects of CI benefits such as teamwork and communication also scored very low.

Table 4. The Benefits of CI in the Irish Pharma Industry.

\begin{tabular}{|c|c|c|}
\hline Benefits of CI & No. of Responses & $\%$ \\
\hline Improved Productivity & & $25 \%$ \\
\hline Improved product quality & & $23 \%$ \\
\hline Achieving Cost Savings & & $14 \%$ \\
\hline Enhanced Staff Efficiency & & $8 \%$ \\
\hline Improved Speed/Timeliness & & $6 \%$ \\
\hline Reduced defect rate in processes & & $4 \%$ \\
\hline Increased Employee Engagement & & $4 \%$ \\
\hline $\begin{array}{l}\text { Improved Standardization of } \\
\text { Processes/Procedures }\end{array}$ & & $3 \%$ \\
\hline Improved Customer/Patient Safety & & $3 \%$ \\
\hline Enhanced Customer/Patient Satisfaction & & $3 \%$ \\
\hline Ensures Compliance & & $3 \%$ \\
\hline Improved Employee Satisfaction and morale & & $2 \%$ \\
\hline $\begin{array}{c}\text { Improved Communication Between the } \\
\text { Departments }\end{array}$ & & $1 \%$ \\
\hline $\begin{array}{c}\text { Increased Understanding of Customer } \\
\text { Wants/Needs }\end{array}$ & & $0.4 \%$ \\
\hline
\end{tabular}

A multiple-choice-type-answer question was asked on the CFFs for CI based on the literature, and respondents were asked to pick five CFFs. The top CFFs to CI (Figure 5) was seen as (1) resistance to a CI culture change (12\%), (2) lack of training and education $(10 \%),(3)$ poor communication about CI from senior management $(9 \%),(4)$ lack of resources (financial, technical, human, etc.) (8\%), and (5) a lack of awareness of the need for LSS and 
its benefits (8\%). Fear of extra regulatory work, e.g., validation as a result of CI projects, also features in the top six CFFs.

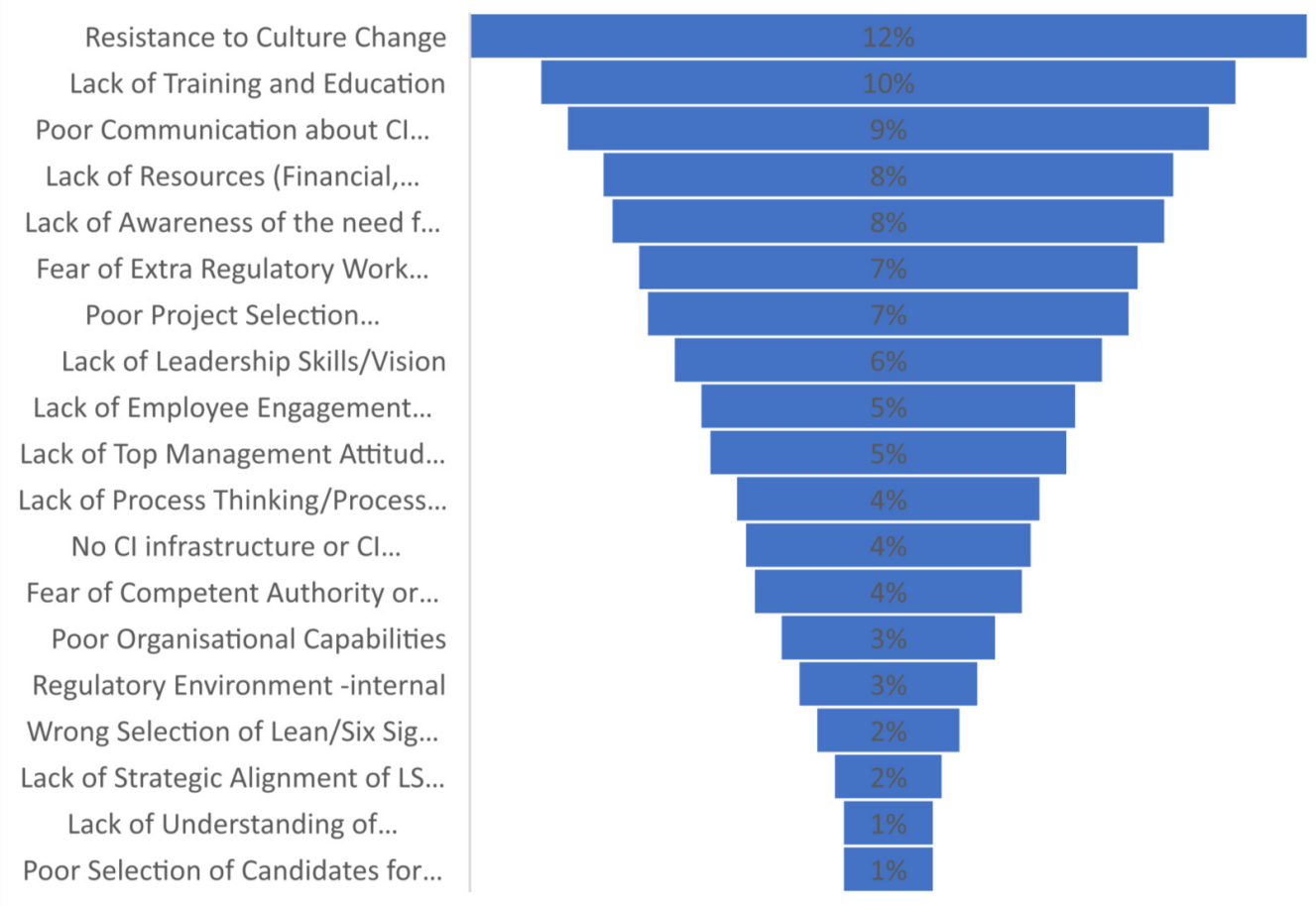

Figure 5. CFF's of CI in the Irish pharma Industry.

The Senior Management and leadership role features as a recurring theme in the top 10 of the questionnaire responses in terms of poor communication about CI from senior management (ranked \#3), lack of leadership skills and vision (ranked \# 8) and lack of top management attitude and commitment (ranked \# 10). This support can be a serious CFF for any CI initiative [47].

Moreover, the finding that only $20 \%$ of respondents felt CI reviews were very integrated into the management review processes and systems supported this finding even if a further $29 \%$ thought it was integrated. As support for CI and training comes from leadership support and direction, as does enabling CI culture, it is not surprising that lack of training and education and resistance to culture change is the second- and third-ranked CFFs after poor communication about CI from senior management. A lack of resources can also be attributed to a lack of support from leadership and an already heavy compliance workload.

The next question asked was, "Which of the following CI tools are utilised in your organisation, or are you aware of it as being utilised (please tick all that applies to your organisation)?" The respondents were provided with several Lean and Six Sigma tools from which to choose and aid in their responses (Figure 6). The top five tools utilised according to the respondents were (1) C\&E, (2) 5 Whys, (3) 5S, (4) process mapping, and (5) brainstorming and FMEA (equal) in order of ranking. The least utilised or recognised tools were Hoshin Kanri (strategic top-down, bottom-up planning), hypothesis testing, and Hejunka (Level scheduling). As Hoshin Kanri and Hejunka are the original Japanese Lean terms, some respondents may not recognise these, or they may be utilised under different names if they are being used.

Just under $100 \%$ of respondents (77) stated they had utilised Cause and Effect analysis or were familiar with it. Over half of the tools listed in the survey were utilised by over $50 \%$ of respondents organisations, with several of the remaining tools utilised by between $25 \%$ and $30 \%$ of respondents. This suggests that CI tools are familiar to these organisations; people have been educated about their use and are familiar with them. As 
97\% of respondents stated that they utilised CI methodologies within their organisations (Lean, LS, SS), this would back up this result of high awareness and use of CI tools.

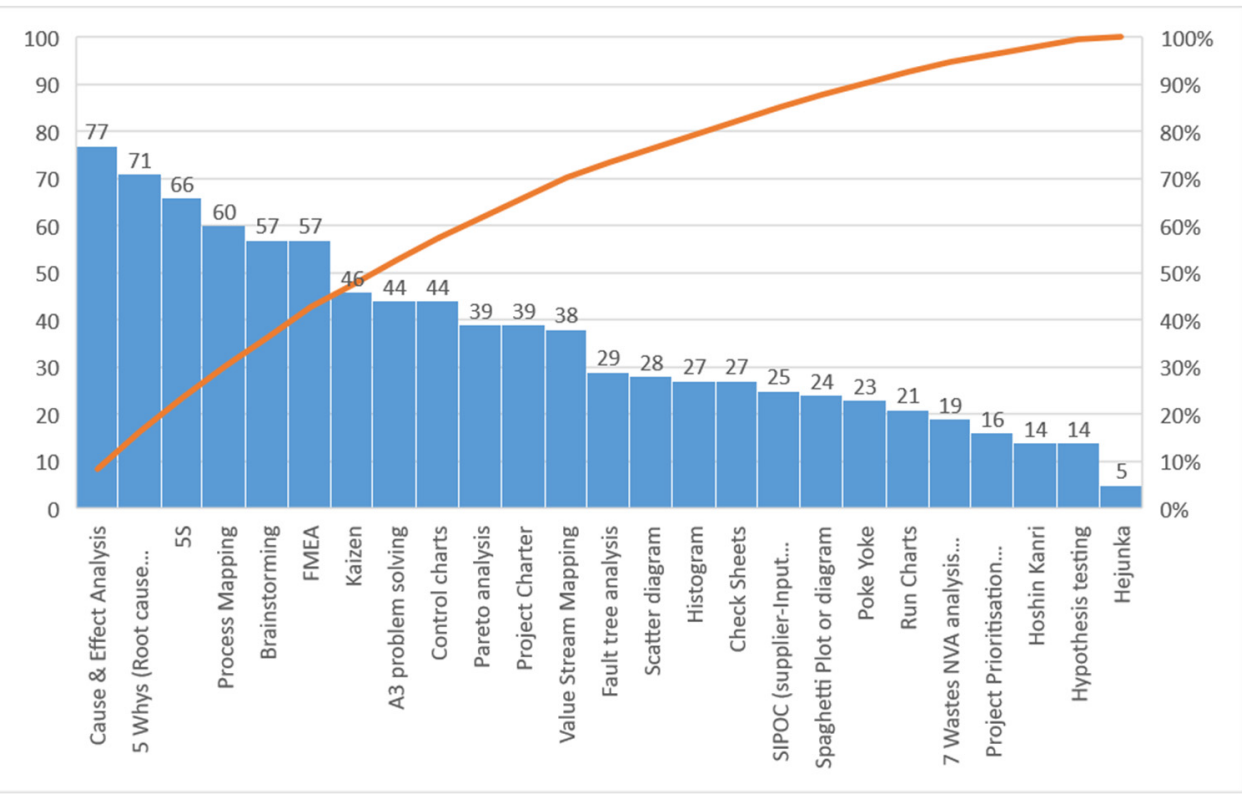

Figure 6. CI tools most utilised in Irish pharma.

A question was asked concerning this to establish if a highly regulated environment is a barrier to continuous improvement programs in Irish pharma. Respondents were given a simple option to answer "yes" or "no" to the question that regulated environments were a barrier to CI. More respondents answered "no" (55\%) to this question and stated that regulatory compliance or regulations were not a barrier to CI in Irish pharma organisations. However, there was a decisive "yes" vote (45\%) in response to the question (Figure 7). The results suggest some evidence to the argument that a highly regulated pharma environment can stifle CI initiatives.

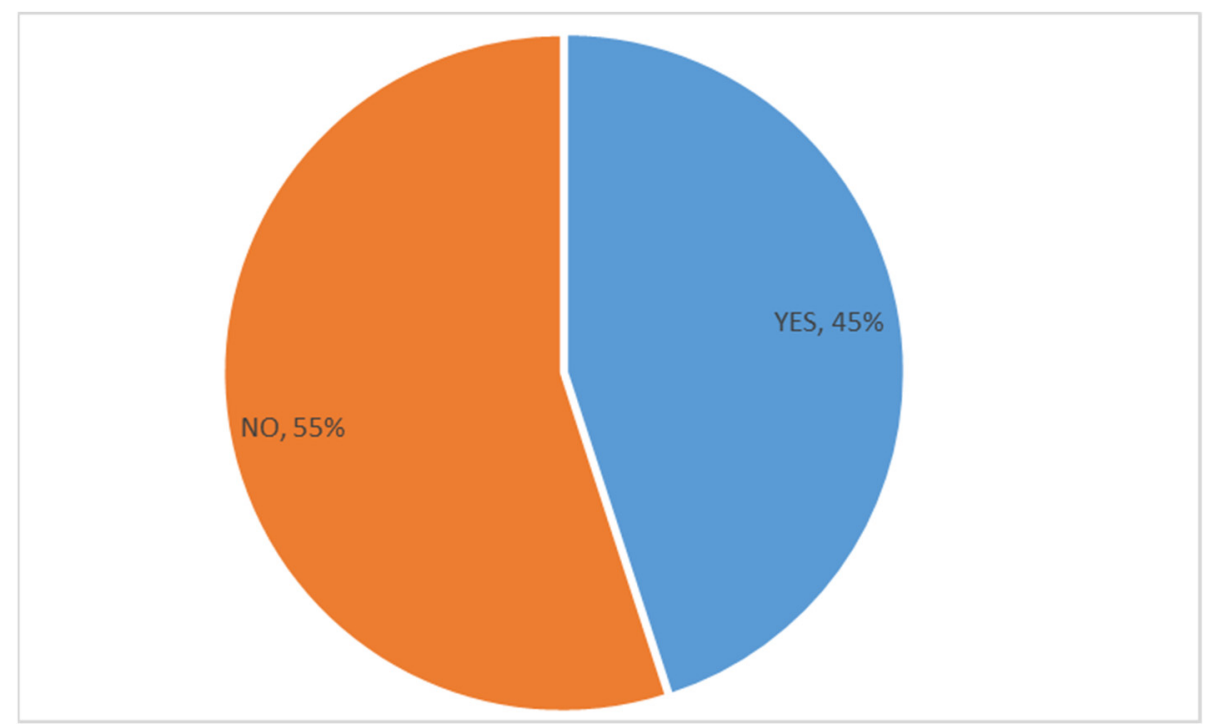

Figure 7. "Does regulatory compliance or a regulated environment/culture at as a barrier to continuous improvement programs in your organisation?". 
This correlates with the literature which has stated that Pharmaceutical manufacturers are reluctant to change processes that are confirmed and validated and accepted as compliant $[13,16,18]$.

Respondents who answered "yes" that they believed that a regulated pharma environment was a barrier to CI deployment and progress were asked another question in relation to specific barriers to CI using a Likert scale (Table 5). The "strongly agree" and "agree" answers to this question were high, as this question was only completed by the $45 \%$ of respondents who had answered that pharma regulations were a barrier to $\mathrm{CI}$. The top reasons highlighted in order of the "strongly agree" rankings by those who felt there were barriers to $\mathrm{CI}$ in regulated industries were, in order of ranking: (1) fear of extra validation activity (44\%), (2) a compliance versus quality culture (42\%), (3) a regulatory culture within the organisation of being "safe" (42\%), and (4) fear of extra regulatory submission workload $(42 \%)$. The combined "strongly agree" and "agree" vote for all of the issues mentioned above was between $70 \%$ and $89 \%$, which indicates that the regulatory environment was deemed a considerable barrier to $\mathrm{CI}$.

Table 5. Reasons for CI barriers in a pharma-regulated organisation.

\begin{tabular}{|c|c|c|c|c|c|}
\hline $\begin{array}{c}\text { Reasons for CI Barriers in Regulated } \\
\text { Environments }\end{array}$ & $\begin{array}{l}\text { Strongly } \\
\text { Agree }\end{array}$ & Agree & $\begin{array}{l}\text { Neither Agree } \\
\text { Nor Disagree }\end{array}$ & Disagree & $\begin{array}{l}\text { Strongly } \\
\text { Disagree }\end{array}$ \\
\hline Fear of extra validation activity & $44 \%$ & $31 \%$ & $19 \%$ & $6 \%$ & $0 \%$ \\
\hline $\begin{array}{l}\text { Compliance v's Quality (closing } \\
\text { issues/investigations within deadlines) }\end{array}$ & $31 \%$ & $39 \%$ & $25 \%$ & $6 \%$ & $0 \%$ \\
\hline Regulatory Culture of being "safe." & $42 \%$ & $47 \%$ & $6 \%$ & $6 \%$ & $0 \%$ \\
\hline $\begin{array}{c}\text { Overdependence on a Continuous Improvement } \\
\text { owner/dept. to drive program }\end{array}$ & $22 \%$ & $36 \%$ & $22 \%$ & $17 \%$ & $3 \%$ \\
\hline $\begin{array}{l}\text { Changes seen as potentially affecting compliance } \\
\text { to Regulations }\end{array}$ & $42 \%$ & $36 \%$ & $22 \%$ & $0 \%$ & $0 \%$ \\
\hline Fear of extra regulatory submission workload & $42 \%$ & $31 \%$ & $19 \%$ & $6 \%$ & $3 \%$ \\
\hline CI seen as a Quality dept initiative & $14 \%$ & $17 \%$ & $22 \%$ & $36 \%$ & $11 \%$ \\
\hline Lack of training & $19 \%$ & $31 \%$ & $22 \%$ & $25 \%$ & $3 \%$ \\
\hline CAPA seen as unwanted extra work & $14 \%$ & $42 \%$ & $14 \%$ & $25 \%$ & $6 \%$ \\
\hline Regulatory department don't see benefits. & $22 \%$ & $22 \%$ & $39 \%$ & $11 \%$ & $6 \%$ \\
\hline Lack of management support & $19 \%$ & $25 \%$ & $28 \%$ & $22 \%$ & $6 \%$ \\
\hline Heavy external audit schedule limits time for CI & $11 \%$ & $25 \%$ & $33 \%$ & $28 \%$ & $3 \%$ \\
\hline
\end{tabular}

A total of $44 \%$ of respondents strongly agreed, and $31 \%$ agreed that fear of extra validation activity is a barrier to CI. "A fear of extra submission workload" as a barrier to CI, while only having a low "strongly agree" vote at $42 \%$, had a $31 \%$ "agree" vote agreeing that it was a barrier factor for CI. The "CAPA system seen as unwanted extra work," having a low "strongly agree" vote of $14 \%$, had the highest "agree" vote as a barrier to CI at $42 \%$.

The barriers of having a "compliance versus quality" culture had a strongly agreement percentage of $31 \%$ and an agree vote of $39 \%$, while a regulatory culture of being "safe" had a $42 \%$ strongly agree vote and a $47 \%$ agree with vote. These two barriers are reflective of a regulatory focus that could stifle CI.

While external audit preparation can be very time-consuming, a heavy external audit schedule as a barrier to CI had a very low "strongly agree" vote of $11 \%$ compared to other barriers offered. However, it had a high $25 \%$ of "agree" votes.

"CAPA was seen as unwanted extra work" while not in the top "strongly agree" barriers to CI had a strongly agree vote and an agree vote of $14 \%$ and $42 \%$ that it was a barrier to CI. CAPA's are seen as time-consuming and extra paperwork [57]. A global medical device manufacturer, Medtronic stated that they spend "about $\$ 150 \mathrm{~m}$ on CAPA" [58]. 
Interestingly, CI, being seen as a quality department initiative, had the highest disagree and strongly disagree vote at $36 \%$ and $11 \%$, respectively, suggesting that CI was generally owned by more than just the quality function. This suggests a positive CI culture across the organisation. This finding also correlates with the previous results that $97 \%$ of the respondents stated CI methods are being utilised in their organisations and that there was a high familiarity and knowledge of CI tools.

\section{Discussion and Implications}

This research has concluded that Irish pharma has adopted and integrated CI methods, with CI methods being utilised and deployed in $97 \%$ of participating manufacturers. The top five tools used for CI according to the respondents were (1) C\&E, (2) 5 Whys, (3) 5S, (4) process mapping, and (5) brainstorming, in order of ranking. These tools would be deemed very traditional basic tools, suggesting usage and engagement in fundamental problem solving and CI. On the other hand, some more complex CI tools, like Hoshin Kanri, Hejunka, and statistical-based hypothesis testing, were the least utilised or recognised tools cited by respondents, suggesting that management could be doing more to train and educate on CI within their organisations.

In terms of the benefits of CI in Irish Pharma organisations, (1) improved productivity, (2) improved quality, and (3) achieving cost savings were highlighted as the top three benefits.

CI tools were "Very Integrated" into the following areas in order of ranking: 1. Corrective \& Preventive Action System (CAPA) (49\%), 2. Deviations (Non-Conformance) processes (46\%), 3. Internal and External Audit systems (44\%), and 4. Pharmacovigilance systems (33\%). This suggests a high integration of CI methods and problem-solving tools into the PQS and QMS. This demonstrates efforts to drive CI practices into the regulatory process. The ICH has also tried to focus on a strong CI approach via ICH 10 and ICH $12[41,44]$.

The findings of this research found the top CFFs to CI were viewed as (1) resistance to a CI culture change, (2) lack of training and education, (3) poor communication about CI from senior management, (4) lack of resources (financial, technical, human, etc.), and (5) a lack of awareness of the need for LSS and its benefits.

Fear of extra regulatory work, e.g., validation as a result of CI projects, also features in the top six CFFs. This CFF is unique to regulated industries and would not have featured in other studies on CFFs for CI in industry.

A total of $55 \%$ of respondents stated that regulatory compliance or regulated environments did not stifle CI in their organisation, but $45 \%$ agreed that it did. The top six reasons highlighted in order of the "strongly agree" rankings by those who felt there were barriers to CI in regulated industries were: (1) fear of extra validation activity, (2) a compliance v's quality culture, (3) a regulatory culture within the organisation of being "safe," and (4) fear of extra regulatory submission workload.

The implications for this study are that it can inform continuous improvement programs in the Irish pharma and wider global pharma industry as to the challenges, CFFs, and barriers to deployment of CI. Apart from the findings on specific CFFs to CI that are common to all organisational types, there is some strong evidence that a regulated environment can be a further barrier to CI deployment in an organisation. Leadership teams can utilise this research to analyse their organisations and assess their readiness in terms of a regulatory environment for CI.. Within the academic community, this study is one of the first focusing on the barriers to CI within a pharma and regulated environment and should aid further study, research, and understanding of CI in regulated environments.

\section{Conclusions, Limitations, and Directions for Further Research}

The research objectives to ascertain the CI methods and tools used for CI (RF\#1), the drivers and benefits for the use of CI (RF\#2), and the CFFs for the deployment of CI (RF\#3) utilised for CI in the Irish Pharmaceutical industry were all met. The additional objective of 
this research to ascertain if the highly regulated nature of the Irish pharmaceutical industry poses a unique and significant barrier to CI methodology deployment and culture (RF\#4) was also presented. In summary, there is evidence of strong CI methods deployment (as $97 \%$ of respondents stated their organisations are utilising CI initiatives) and CI programs being driven to achieve productivity, quality and cost savings. CFFs to CI deployment are not dissimilar to other sectors, but $45 \%$ of respondents believed that a highly regulated environment can pose an additional barrier or CFF to CI.

This research has implications for deployment and understanding of CI programme implementation and the pharmaceutical industry in general. An organisational environment that is highly regulated and engaged with regulatory compliance can experience barriers to CI deployment. Understanding these barriers aid CI program deployment.

The limitations of this study are that it was conducted in the Irish pharma industry and would be pertinent to expand other global pharma clusters. However, the medical device industry is also highly regulated, and the pharmaceutical industry is perhaps as if not more highly regulated than the device industry, so there is an opportunity for comparative studies.

There is also an opportunity to investigate and learn about the perceived differences in the study's findings within different countries and within different regulatory jurisdictions outside of the ICH regions.

Finally, more in-depth exploratory research in qualitative interviews and specific case studies within the pharma industry would help obtain further insights into the topic of interest.

Author Contributions: Conceptualization, O.M. and J.A.; methodology, O.M., M.S., and S.D.; formal analysis, O.M., M.S., and J.A.; writing—original draft preparation, O.M., M.S., S.D., and J.A.; writingreview and editing, O.M., M.S., S.D., and J.A.; supervision, O.M. All authors have read and agreed to the published version of the manuscript.

Funding: This research received no external funding.

Institutional Review Board Statement: Not applicable.

Informed Consent Statement: Not applicable.

Data Availability Statement: Not applicable.

Conflicts of Interest: The authors declare no conflict of interest.

\section{Appendix A}

Survey Questions

Q1. What country/continent are you based in?

Q2. What industry are you in?

Q3. What function or department do you work in? Please tick as appropriate.

Q4. How many years of experience do you have in continuous improvement methodologies? Q5. Which of the following methodologies and systems have you worked with or are aware of as being applied in your organization?

- Lean

- Six Sigma

- LSS

- $\quad$ None of the above

Q6. How integrated are CI into the following quality subsystem or subsystems (Likert scale):

1. CAPA (Corrective and Preventive Action) System

2. Supplier Correct Action (SCAR) System

3. Design Assurance

4. Pharmacovigilance/Post Market Surveillance/Customer Complaints/Vigilance Systems

5. Non Conformance System/Deviation Mgmt

6. Internal and External Audit System

7. Agenda item in Management Review process 
Q7. Do you feel that a regulatory compliance or regulated environment/culture stifles continuous improvement programs in your organization? Yes or No.

Q8. Why do you feel that a regulatory environment can stifle CI? Tick all that apply.

- $\quad$ Lack of management support

- $\quad$ CAPA seen as extra work

- $\quad$ Lack of training

- Heavy external audit schedule-no time for CI

- Culture of being safe

- $\quad$ Fear of extra validation associated with $\mathrm{CI}$ improvements

- $\quad$ Fear of extra regulatory submission workload

- $\quad$ Compliance v's quality (closing issues within deadlines)

- Regulatory department does not see benefits

- Changes seen as potentially affecting compliance to regulations

- $\quad$ Overdependence on a CI owner/dept to drive CI program

- $\quad$ I seen as a quality department initiative

Q9. What are the internal drivers of CI in your organisation? (Likert scale)

- Customer focus/patient

- $\quad$ Safety focus

- $\quad$ Productivity focus

- Quality focus

- $\quad$ Regulatory focus

- $\quad$ Financial focus

Q10. Please tick what you think are the top 5 benefits of CI to your organization? Tick 5 of the benefits listed.

Q11. Please tick what you think are the top 5 Critical Failure Factors (CFFs) to the use of CI methodologies in your organization? (pick from list)

Q12. Which of the following tools have you utilised in your current organization as part of CI initiatives or are you aware of as being utilised? (Please tick all from the list that applies to your organisation)

Q13. Which quality system or quality standard do you adhere to in your organization? Tick all that apply if known. 


\section{References}

1. IDA Bio-Pharmaceuticals \& Biotechnology Ireland. Available online: https://www.idaireland.com/doing-business-here/ industry-sectors/bio-pharmaceuticals (accessed on 14 November 2021).

2. Irish Pharmaceutical Heathcare Association Contribution to the Irish Economy. Available online: https://www.ipha.ie/aboutthe-industry/contribution-to-the-irish-economy/ (accessed on 14 November 2021).

3. BioPharmaChem Ireland A Strategy for BioPharmaChem Manufacturing in Ireland 2019-2023. Available online: https: //www.ibec.ie/influencing-for-business?ppc_keyword=ibec\&gclid=Cj0KCQiAhMOMBhDhARIsAPVml-Et-psaCH1IzFpt3 Hu8At3XK4HeMiK-t3RvTH55HzZbE-XbfRNShY4aApciEALw_wcB (accessed on 14 November 2021).

4. Draguet, V. A Pharmaceutical Strategy for Europe. Available online: https://ec.europa.eu/health/human-use/strategy_en (accessed on 17 November 2021).

5. Burke-Kennedy, E. Irish Exports Hit Record $€ 15.7 \mathrm{bn}$ in March as Demand for Medicines Surges. Available online: https://www. irishtimes.com/business/economy/irish-exports-hit-record-15-7bn-in-march-as-demand-for-medicines-surges-1.4254319 (accessed on 14 November 2021).

6. Purnhagen, K.P. The Challenges of Globalization in Pharmaceutical Law-Is an International Drug Approval System Modeled after the European System Worth Considering? Food Drug Law J. 2008, 63, 623-645.

7. Bilanin, M.; Ahern, S.; Colao, M.; Campa, C.; Geldhof, G. ICH Q12 Implementation from an Industry Perspective. La Vague 2017. Available online: https:/ / www.a3p.org/en/ich-q12-implementation/ (accessed on 18 November 2021).

8. Lee, J. What Is Past Is Prologue: The International Conference on Harmonization and Lessons Learned from European Drug Regulations Harmonization. Univ. Pa. J. Int. Law 2005, 26, 151.

9. Nenni, M.E.; Giustiniano, L.; Pirolo, L. Improvement of Manufacturing Operations through a Lean Management Approach: A Case Study in the Pharmaceutical Industry. Int. J. Eng. Bus. Manag. 2014, 6, 24. [CrossRef]

10. Boccardelli, P.; Grandi, A.; Magnusson, M.; Oriani, R. The Value of Managerial Learning in R\&D. In Strategy in Transition; Wiley: Hoboken, NJ, USA, 2009.

11. Dale, B.G. Sustaining a Process of Continuous Improvement: Definition and Key Factors. TQM Mag. 1996, 8, 49-51. [CrossRef]

12. Gonzalez, R.V.D.; Martins, M.F. Capability for Continuous Improvement: Analysis of Companies from Automotive and Capital Goods Industries. TQM J. 2016, 28, 250-274. [CrossRef]

13. Byrne, B.; McDermott, O.; Noonan, J. Applying Lean Six Sigma Methodology to a Pharmaceutical Manufacturing Facility: A Case Study. Processes 2021, 9, 550. [CrossRef]

14. Chowdary, B.V.; George, D. Improvement of Manufacturing Operations at a Pharmaceutical Company. J. Manuf. Technol. Manag. 2012, 23, 56-75. [CrossRef]

15. Nicholas, J. Line Balancing Manual Assembly Processes Using a Kaizen Blitz Approach in a Highly Regulated Industry. 2019, Volume 2. Available online: https://books.google.co.jp/books?hl=zh-CN\&lr=\&id=mZgEBdQhjAAC\&oi=fnd\&pg=PR9\&dq= Line+Balancing + Manual + Assembly+Processes + Using $+a+$ Kaizen+Blitz + Approach + in $+a+$ Highly + Regulated + Industry \&ots=91 xuIamUHQ\&sig=8IPDJsssJPvLy-j-VX-J_QHxkqc\&redir_esc=y\#v=onepage\&q\&f=false (accessed on 18 November 2021).

16. Vetalice, J.A. Review of Study Results: FDA Impact on U.S. Medical Technology Innovation-BONEZONE. Available online: https:/ / bonezonepub.com/2010/12/31/review-of-study-results-fda-impact-on-us-medical-technology-innovation/ (accessed on 30 June 2021).

17. Sreedharan, V.R.; Sunder, M.V. Critical Success Factors of TQM, Six Sigma, Lean and Lean Six Sigma: A Literature Review and Key Findings. Benchmarking Int. J. 2018, 25, 3479-3504. [CrossRef]

18. Pavlović, K.; Božanić, V. Lean and Six Sigma Concepts: Application in Pharmaceutical Industry. Int. J. Qual. Res. 2012, 6, 23-28.

19. Garza-Reyes, J.A.; Betsis, I.E.; Kumar, V.; Radwan Al-Shboul, M.A. Lean Readiness - the Case of the European Pharmaceutical Manufacturing Industry. Int. J. Product. Perform. Manag. 2018, 67, 20-44. [CrossRef]

20. O'Rourke, D.; Greene, A. Lean Manufacturing Practice in a CGMP Environment. Pharm. Technol. Eur. 2006, 18, 33-40.

21. Cavallaro, F.; Lugg-Widger, F.; Cannings-John, R.; Harron, K. Reducing Barriers to Data Access for Research in the Public Interest-Lessons from Covid-19. Available online: https://blogs.bmj.com/bmj/2020/07/06/reducing-barriers-to-data-accessfor-research-in-the-public-interest-lessons-from-covid-19/ (accessed on 18 November 2021).

22. Zollo, M.; Winter, S. Deliberate Learning and the Evolution of Dynamic Capabilities. Organ. Sci. 2002, 339-351. [CrossRef]

23. Mauri, F.; Garetti, M.; Gandelli, A. A Structured Approach to Process Improvement in Manufacturing Systems. Prod. Plan. Control 2010, 21, 695-717. [CrossRef]

24. What's the Difference between Pharmaceutical and Biotechnology? IMorgan McKinley Recruitment. Available online: https: / / www.morganmckinley.com/ie/article/difference-between-pharmaceutical-and-biotechnology (accessed on 14 November 2021).

25. Alqahtani, S.; Seoane-Vazquez, E.; Rodriguez-Monguio, R.; Eguale, T. Priority Review Drugs Approved by the FDA and the EMA: Time for International Regulatory Harmonization of Pharmaceuticals? Pharmacoepidemiol. Drug Saf. 2015, 24, 709-715. [CrossRef] [PubMed]

26. HPRA Quality Defects. Available online: http://www.hpra.ie/homepage/medicines/quality-information/quality-defects (accessed on 17 November 2021).

27. Allison, G.; Cain, Y.T.; Cooney, C.; Garcia, T.; Bizjak, T.G.; Holte, O.; Jagota, N.; Komas, B.; Korakianiti, E.; Kourti, D.; et al. Regulatory and Quality Considerations for Continuous Manufacturing. May 20-21, 2014 Continuous Manufacturing Symposium. J. Pharm. Sci. 2015, 104, 803-812. [CrossRef] 
28. Witcher, M. Integrating Development Tools into the Process Validation Lifecycle to Achieve Six Sigma Pharmaceutical Quality. Bioprocess. J. 2018, 17, 1-11. [CrossRef]

29. FDA Guidance for Industry: CMC Postapproval Manufacturing Changes to Be Documented in Annual Reports; FDA: Silver Spring, MD, USA, 2014; Volume 16.

30. Miglani, A.; Saini, C.; Musyuni, P.; Aggarwal, G. A Review and Analysis of Product Recall for Pharmaceutical Drug Product. J. Generic Med. 2021, 17411343211033887. [CrossRef]

31. Bloomberg J\&J Sees 'Significant Costs' in 2011 to Fix Recalls-Bloomberg. Available online: https://www.bloomberg.com/news/ articles/2011-01-25/j-j-profit-declines-12-on-product-recalls-2011-outlook-trails-forecast (accessed on 18 November 2021).

32. Hall, K.; Stewart, T.; Chang, J.; Freeman, M.K. Characteristics of FDA Drug Recalls: A 30-Month Analysis. Am. J. Health-Syst. Pharm. AJHP Off. J. Am. Soc. Health-Syst. Pharm. 2016, 73, 235-240. [CrossRef]

33. Anonymous International Collaboration on GMP Inspections. Available online: https://www.ema.europa.eu/en/humanregulatory/research-development/compliance/good-manufacturing-practice/international-collaboration-gmp-inspections (accessed on 18 November 2021).

34. FDA. Mutual Recognition Agreement (MRA); FDA: Silver Spring, MD, USA, 2021.

35. Makuch, R.W.; Shi, R. Comparison of Drug Approvals in Europe Versus the United States: An Analysis of Discrepancies Between Drug Products Reviewed by EMA and FDA. Ther. Innov. Regul. Sci. 2014, 48, 362-366. [CrossRef] [PubMed]

36. Makower, J.; Meer, A.; Denend, L. FDA Impact on US Medical Technology Innovation. 2010. Available online: http: / /www.medtecheurope.org/wp-content/uploads/2015/09/01112010_FDA-impact-on-US-medical-technology-innovation_ Backgrounder.pdf (accessed on 18 November 2021).

37. ICH ICH Official Web Site: ICH. Available online: https:/ /ich.org/ (accessed on 18 November 2021).

38. Škrnjug, I.; Uzeirbegović, S.; Romčević, M.L.; Tomić, S.; Meyer, H.; Conrad, C. Mutual Recognition in the European System: A Blueprint for Increasing Access to Medicines? Regul. Toxicol. Pharmacol. 2019, 106, 270-277. [CrossRef]

39. ECA FDA Adopts ICH Q12-ECA Academy. Available online: https://www.gmp-compliance.org/gmp-news/fda-adopts-ich-q12 (accessed on 18 November 2021).

40. FDA. International Regulatory Harmonization; FDA: Silver Spring, MD, USA, 2020.

41. European Medicines Agency ICH Guideline Q10 on Pharmaceutical Quality System-Step 5. Available online: https://www.ema. europa.eu/en/ich-q10-pharmaceutical-quality-system (accessed on 18 November 2021).

42. Boylan, B.; McDermott, O.; Kinahan, N.T. Manufacturing Control System Development for an In Vitro Diagnostic Product Platform. Processes 2021, 9, 975. [CrossRef]

43. National Academies of Sciences, Engineering, and Medicine. Barriers to Innovations in Pharmaceutical Manufacturing: Proceedings of a Workshop-in Brief; The National Academies Press: Washington, DC, USA, 2020. [CrossRef]

44. ICH ICH Q12 Technical and Regulatory Considerations for Pharmaceutical Product Lifecycle Management. Available online: https:/ / www.ema.europa.eu/en/ich-q12-technical-regulatory-considerations-pharmaceutical-product-lifecycle-management (accessed on 18 November 2021).

45. Chatterjee, B. Applying Lean Six Sigma in the Pharmaceutical Industry, 1st ed.; Routledge: London, UK, 2014.

46. Antony, J.; Krishan, N.; Cullen, D.; Kumar, M. Lean Six Sigma for Higher Education Institutions (HEIs): Challenges, Barriers, Success Factors, Tools/Techniques. Int. J. Product. Perform. Manag. 2012, 61, 940-948. [CrossRef]

47. Albliwi, S.; Antony, J.; Abdul Halim Lim, S.; van der Wiele, T. Critical Failure Factors of Lean Six Sigma: A Systematic Literature Review. Int. J. Qual. Reliab. Manag. 2014, 31, 1012-1030. [CrossRef]

48. Full Article: Synergies between Critical Success Factors of Lean Six Sigma and Public Values. Available online: https://wwwtandfonline-com.libgate.library.nuigalway.ie/doi/full/10.1080/14783363.2017.1383153 (accessed on 5 September 2021).

49. Antony, J.; Snee, R.; Hoerl, R. Lean Six Sigma: Yesterday, Today and Tomorrow. Int. J. Qual. Reliab. Manag. 2017, 34, 1073-1093. [CrossRef]

50. Barclay, R.C.; Cudney, E.A.; Shetty, S.; Antony, J. Determining Critical Success Factors for Lean Implementation. Total Qual. Manag. Bus. Excell. 2021, 1-15. [CrossRef]

51. Ball, H.L. Conducting Online Surveys. J. Hum. Lact. Off. J. Int. Lact. Consult. Assoc. 2019, 35, 413-417. [CrossRef]

52. Power, A. LinkedIn: Facebook for Professionals? Br. J. Midwifery 2015, 23, 196-198. [CrossRef]

53. Easterby-Smith, M.; Thorpe, R.; Jackson, P.R. Management Research; SAGE: Newbury Park, CA, USA, 2012; ISBN 1-4462-6026-7.

54. Quality Digest Magazine. Available online: https://www.qualitydigest.com/mar08/articles/05_article.shtml (accessed on 15 November 2021).

55. Antony, J.; Gupta, S.; Sunder M., V.; Gijo, E.V. Ten Commandments of Lean Six Sigma: A Practitioners' Perspective. Int. J. Product. Perform. Manag. 2018, 67, 1033-1044. [CrossRef]

56. Wagner, K.; Schulze, U.; Farber, A. Lean Comes to Pharma. Pharm. Exec. 2009. Available online: www.Pharmexec.Com/LeanComes-Pharma-0 (accessed on 25 February 2016).

57. Haigney, S. Responding to FDA CAPA Requests. Pharm. Technol. 2021, 45, 52-57.

58. Schmitt, S. How A Team Led By Medtronic Quality Experts Plans To Stand Up To "A Monster Called CAPA"-And Make It "Cool". Available online: https:/ / medtech.pharmaintelligence.informa.com/MT124933/How-A-Team-Led-By-MedtronicQuality-Experts-Plans-To-Stand-Up-To-A-Monster-Called-CAPA--And-Make-It-Cool (accessed on 15 August 2021). 